\title{
Reinvención de marcas territorio a través de la organización de eventos: Cuenca y su riqueza paleontológica
}

\author{
CRISTINA GONZÁLEZ OÑATE \\ Universidad Jaume I de Castellón \\ onate@uji.es \\ SONIA MARTÍNEZ BUENO \\ Fundación de Cultura Ciudad de Cuenca \\ bpmvillaroman@hotmail.com
}

\begin{abstract}
Resumen
Los eventos permiten al consumidor, a través de la experiencia directa, asociar unos determinados valores a una marca (de un producto, servicio o territorio). Esta comunicación tiene como objetivo determinar hasta qué punto esa herramienta del marketing puede contribuir a la creación de marcas territorio y de imágenes de marca capaces de aportar un valor diferencial al destino turístico (una provincia, un territorio y, sobre todo, una ciudad). Concretamente se analizará el caso del yacimiento paleontológico de Lo Hueco y del futuro evento asociado al mismo, y se propondrá un nuevo enfoque de la marca territorio conquense basada en la proyección social de los dinosaurios.
\end{abstract}

Palabras clave: Marca, marca territorio, imagen de marca, evento, destino turístico.

Reinvent branding territory through the organization
of events: Cuenca and its paleontological richness

\begin{abstract}
Events allow the consumer through direct experience, associate certain values to a brand (of a product, service or territory). This communication aims to determine to what extent a marketing tool, organization of events, can contribute to the creation of brands territory and brand images capable of providing a differential value the tourist destination (a province, territory and, above all, a city). Specifically, we analyze the case of the paleontological site of Lo Hueco and of the future event associated with
\end{abstract}


the same and will propose a new approach to mark territory of Cuenca based on the social projection of the dinosaurs.

Key words: Brand, brand territory, brand image, event, tourist destination.

Sumario: 1.- Introducción. 2.- Una aproximación al concepto de marca territorio. 3.La organización de eventos como constructor de imagen en períodos de crisis: creación de marca territorio. 3.1.- Eventos y comunicación: tipología. 4.- Cuenca y sus yacimientos paleontológicos. Los dinosaurios en la construcción de la nueva marca territorio conquense. 4.1.- Análisis de la marca "Cuenca, naturaleza y cultura". 4.2.Dimensión social de los dinosaurios: algunos ejemplos. 4.3.- Los yacimientos paleontológicos conquenses. 5.- El complejo de Lo Hueco: reinvención de la marca territorio conquense a través del desarrollo de eventos. 5.1.- Reinvención de la marca territorio de Cuenca. 6.- Conclusiones. 7.- Referencias bibliográficas.

\section{Introducción.}

$\mathrm{Al}$ igual que la palabra nos hizo humanos y permitió la comunicación entre las personas, su representación simbólica dio origen a la escritura. Y cada conjunto de símbolos (o lengua) posee grafías y sonidos que la diferencian del resto. Las ciudades y territorios (al igual que las empresas) en cuanto que entes organizados, también necesitan comunicarse con los actores que intervienen en el mercado y, a la vez, identificarse y distinguirse dentro del entorno que habitan. La marca ha sido, y es, uno de los mecanismos más utilizados para establecer esa nota distintiva y transmitirla al consumidor. En el momento presente, el turismo es uno de los sectores que más contribuye al desarrollo económico de los países y las regiones (Kandampully, 2000: 12). Pero también es verdad que, debido a la actual crisis mundial, está sumido en un proceso de transformación importante: incremento de la competencia en los precios, resurgimiento o aparición de nuevos destinos, uso de Internet, disminución de pernoctaciones, menor gasto medio por turista, mayor preocupación por el medio ambiente, por la calidad y por el turismo sostenible, etc.

La presente comunicación ahonda en la contribución que, en plena recesión económica, la marca y la imagen de un territorio tienen en el desarrollo turístico del mismo. $\mathrm{Y}$ cómo la reinvención de las mismas a través del diseño de eventos puede contribuir a establecer diferencias, en la mente de los consumidores, entre los diversos destinos turísticos. En consecuencia, parece 
oportuno realizar una breve aproximación al concepto de marca territorio, a la organización de eventos y a sus aportaciones a la génesis y difusión de la marca territorio. Se mostrarán algunos ejemplos de su uso y, para finalizar y centrándonos en Cuenca, se propondrá un modelo a aplicar que redefina la marca territorio de la provincia aprovechando su riqueza paleontológica y la proyección social de los dinosaurios.

\section{Una aproximación al concepto de marca territorio.}

Parece claro y evidente que, al igual que en el resto de sectores, también se hace necesario para un territorio o ciudad destacar por encima de la uniformidad global preponderante y diferenciarse de sus competidores. El marketing, y algunas de sus herramientas como la publicidad o el branding, son los encargados de crear y suministrar al consumidor un universo de imágenes (también en el ámbito de los territorios). La marca ha trascendido su dimensión puramente comercial para entrar de lleno en el campo de la comunicación (Semprini, 1995: 233). Para Keller (2008: 720), la marca de un país (y esto es de plena aplicación a una región, una ciudad o cualquier territorio) aporta rasgos racionales, tangibles, simbólicos, emocionales e intangibles que son capaces de distinguir un destino turístico de otros (competidores directos) que pueden satisfacer la misma necesidad. De ahí su importancia y papel decisivo como variable estratégica del marketing turístico. Muchas son las definiciones que podemos encontrar de marca de destino (World Tourism Organization and the European Travel Comission, 2009: XVII). Sin embargo, una de las más completas que existen es la aportada por Blain, Levy y Brent Ritchie:

La creación de un nombre, símbolo, logotipo u otro grafismo que identifica y distingue un destino; que comporta la promesa de una experiencia memorable de viaje que se asocia exclusivamente con el destino; y que sirve para consolidar y reforzar la conexión emocional entre el visitante y el destino; que reduce los costes de búsqueda del consumidor y el riesgo percibido; todo con el objetivo de crear una imagen de destino que influya positivamente en la elección del destino por parte del consumidor. (Blain, Levy y Ritchie, 2005: 337)

Callarisa Fiol (2010: 12) introduce el término de marca territorio y la define como: un concepto que recoge las características propias y diferenciales de un territorio y propone una oferta de valor para los diferentes colectivos con los que interactúa, 
dotándola de una expresión gráfica que facilite su actividad de comunicación. La marca territorio se convierte así en un referente comunicativo, en el continente que aglutina el conjunto de características singulares y rasgos diferenciales de un lugar para, a partir de ellos, generar una imagen de marca cargada de atributos positivos que ayuden a mejorar la competitividad global y a trasmitirla a todos los públicos receptores, sin limitarse a turistas o visitantes. Porque, como expone Huertas (2010: 4), la marca territorio es más que una marca de destino al trascender el ámbito puramente turístico y extenderse a otros sectores: inversores, empresarios, residentes, etc.

\section{La organización de eventos como constructor de imagen en períodos de crisis: creación de marca territorio.}

Luciano Cassisi (2006) afirma que la marca de hoy es el referente de una entidad que condensa tanto su área de actuación, como su estilo, jerarquía, valores, etc. Es un fenómeno de imagen. Es probable que muy pocos consumidores hayan visitado la Cordillera del Himalaya y, sin embargo, prácticamente todos han conformado en su mente una imagen de la misma. Y esa imagen, en el caso de un destino turístico que no se conoce a priori, es la que puede determinar la decisión de llevar a cabo un viaje al lugar o no. Por lo tanto, parece evidente la importancia de la creación y consolidación de determinadas imágenes inducidas a la hora de diseñar la construcción de una identidad territorial (Jiménez y San Eugenio, 2009: 279) y, por supuesto, una marca territorio.

En este apartado se tratará de poner de relieve la contribución que el desarrollo de algunos eventos puede tener en la creación de una marca territorio y en su capacidad para asociar determinados valores, sensaciones y emociones con la imagen de dicha marca.

Jiménez y San Eugenio (2009: 280), citando a Ritchie y Hudson, establecen cuales son los cinco puntos básicos que se deben tener en cuenta a la hora de organizar un evento cuyo objetivo sea construir una imagen de marca territorio. El primero es la necesidad de llevar a cabo una investigación exhaustiva y rigurosa que permita establecer y delimitar cuales son las expectativas que el público tiene con respecto al evento y al territorio en cuestión. Es decir, qué esperan de uno y de otro. El segundo es elaborar un plan de trabajo detallado que ayude a diseñar un evento en función de las necesidades detectadas y los objetivos planteados y que, además, 
permita extraer conclusiones a posteriori y en cada una de las fases del evento. El tercer punto lo centran en la necesidad constante de realizar estudios cualitativos y cuantitativos en cada fase del proyecto y analizar las experiencias desarrolladas en otros lugares. Toda esa información recopilada permitirá elaborar estrategias de comunicación ( $4^{\circ}$ punto) dirigidas, principalmente, a resaltar los aspectos emocionales de la marca territorio y a crear vínculos afectivos hacia la misma. Por último (5 punto), los autores recalcan la necesidad de contar con un sólido soporte empresarial e institucional que facilite y permita el desarrollo de una estrategia de construcción de imagen de marca territorio basada en la organización de eventos.

Por otro lado, centran su atención en las imágenes inducidas que la organización de un evento puede provocar "in situ". Como dichos autores afirman: $e l$ evento, en realidad, puede devenir un catalizador de imágenes, un verdadero creador de imaginarios capaces de generar y consolidar una marca de ciudad en conjunto (Jiménez y San Eugenio, 2009: 282). Por tanto, dentro de la estrategia de comunicación, un evento puede contribuir a la promoción turística de un territorio $\mathrm{y}$, al mismo tiempo, ayudar en la elaboración de la marca territorio. De hecho, si el evento se limitara a vender un lugar como un simple destino turístico se estaría desaprovechando un potencial comunicacional que puede tener influencias positivas en la imagen de marca territorio. Joan Costa (2004: 136), a propósito del concepto de sistema Inter Media (donde el individuo no se limita a ser un receptor pasivo sino que se convierte en un emisor activo que interactúa con el entorno), afirma que al organizar un evento se crea un discurso que se convierte en un espacio envolvente, un entorno interactivo que se extiende a los lugares, a los objetos $y$, también, al tiempo. Es decir, se construye una imagen de marca territorio al tiempo que se establecen vínculos afectivos con esa identidad territorial que transmite la imagen de dicha marca. Un evento facilita que el visitante entre en contacto directo con el lugar, sus edificios y monumentos, con sus habitantes, con sus productos y servicios...Un evento comunica la autenticidad de un territorio. Costa (2004: 137) habla de la confluencia de cuatro ámbitos diferenciados (ámbito material de la realidad, ámbito simbólico de los mensajes emitidos, ámbito comunicacional de las percepciones, las reacciones, las decisiones y las interpretaciones que los individuos hacen del ámbito material y simbólico, y ámbito experiencial del consumo, de los productos, de los lugares, de los servicios y las personas que los regentan, de la percepción de la calidad, de las satisfacciones y las emociones. Un evento bien diseñado y realizado puede provocar, por un lado, la afluencia de 
turistas a una determinada zona o lugar y, por otro, puede contribuir poderosamente a la construcción de una marca territorio a la que se asociarán valores identitarios positivos. En definitiva, el desarrollo de eventos es una herramienta imprescindible en cualquier estrategia comunicativa que puede facilitar el acercamiento y conocimiento, por parte del público objetivo, de los recursos tangibles e intangibles, al tiempo que contribuye al desarrollo sostenible de un lugar cimentado sobre una poderosa marca territorio.

\subsection{Eventos y comunicación: tipología}

Como ha quedado patente en el apartado anterior, el desarrollo de un evento contribuye a asociar unos determinados valores con la marca de un territorio y a elaborar, en la mente del individuo, una imagen del mismo. Según Jiménez y San Eugenio (2009: 287), tres son los niveles de comunicación que se pueden alcanzar con el desarrollo de un evento:

- Comunicación institucional-empresarial. Se ha evolucionado de acciones puramente informativas a acciones cuyo objetivo es generar imagen corporativa de las administraciones públicas. $\mathrm{Y}$, en este contexto, la organización de eventos se muestra como una herramienta eficaz para transmitir imagen de marca basada en la experiencia vivida in situ.

- Marketing de ciudades. Puede entenderse como el proceso a través del cual se crea o cambia la imagen de una ciudad (o de cualquier territorio) con la finalidad de asociarla a unos valores concretos, más allá de una identidad puramente visual (marca gráfica), aunque ese sea su punto de partida. Algunos autores lo definen como citymarketing implicativo (Puig, 2009: 183). Se trata de diseñar un modelo de ciudad o territorio $y$, a partir de él, crear una marca territorio. Es ahí donde la realización de un evento puede contribuir a transmitir emociones, sentimientos y conocimiento sobre ese lugar y a posibilitar la construcción de una marca basada en la experiencia vivencial que reciben los participantes.

- Comunicación turística. La actividad turística implica el desplazamiento del individuo al lugar de destino y, por tanto, el desarrollo de una experiencia personal y la creación de una imagen sobre el sitio en cuestión. Pero en un entorno tan competitivo como el actual y con un grado de uniformidad tan elevado entre los territorios, resulta primordial que la imagen que percibe a priori el con- 
sumidor sea capaz de proporcionar, por sí sola, la clave de la elección del destino. La comunicación en este sector ha ido evolucionando desde la información a la emoción, apelando cada vez más a los sentimientos y construyendo argumentaciones emocionales y persuasivas. En este contexto, la organización de un evento permite transmitir, por un lado, los beneficios subjetivos de un destino $y$, por otro, los racionales $u$ objetivos, al tiempo que se construye una imagen de marca vinculada a un territorio.

A lo largo de los últimos veinte años en España han tenido lugar algunos grandes eventos con desiguales repercusiones, tanto a nivel económico como social o comunicativo (Exposición Universal de Sevilla, Juegos Olímpicos de Barcelona, Copa América, Expo Zaragoza...). El impacto de estos eventos ha dependido, en la mayoría de las ocasiones, de los planes de desarrollo organizados por las administraciones públicas en cada caso. Es importante reseñar que cualquier evento de esas magnitudes debería ser contemplado por los agentes impulsores del mismo como un eficaz instrumento de desarrollo local y regional y, por tanto, las estrategias diseñadas para ejecutarlos deberían ir más allá de la construcción de infraestructuras necesarias para llevarlo a cabo, articulando también planes de viabilidad y usos de las instalaciones finales y desarrollando medidores de rentabilidad de imagen corporativa de los lugares que los acogen. En cualquier caso, parece evidente que las ciudades que son sede de algún evento suelen potenciar su imagen tanto en el interior como en el exterior de España y que ese factor contribuye a su desarrollo económico y social.

\section{Cuenca y sus yacimientos paleontológicos. Los dinosaurios en la cons- trucción de la nueva marca territorio conquense}

Para abordar este epígrafe es necesario plantear dos interrogantes básicos:

- ¿Resulta apropiada la actual marca de Cuenca a la hora de definir y diferenciar esta provincia del resto de su Comunidad o de otras alternativas de turismo interior?

- ¿La proyección social de los dinosaurios puede servir como elemento novedoso, diferenciador y distintivo en la creación de una nueva marca territorio para Cuenca?

A continuación, se tratarán de buscar las respuestas a esas preguntas. 


\subsection{Análisis de la marca "Cuenca, naturaleza y cultura"}

La actual imagen corporativa de Cuenca se implantó como consecuencia directa de la puesta en marcha del Plan de Dinamización Turística y se creó, como se explica en el propio Manual de Identidad Corporativa (2001: 3), con el objetivo de dotar a la ciudad de Cuenca de una imagen gráfica y de un sistema de comunicación propios, que permitan al público al que nos dirigimos identificarla y diferenciarla del resto de destinos turísticos de España. Para su desarrollo se tuvieron en cuenta dos de las características más importantes de la ciudad y que mejor la definen: el entorno natural (una situación geográfica privilegiada, entre las hoces del río Júcar y el Huécar) y la riqueza cultural (con especial hincapié en las artes plásticas). La marca turística está formada por tres partes gráficas bien diferenciadas que constituyen lo que se define como elementos básicos de identificación, a saber, un símbolo, un logotipo y un lema.

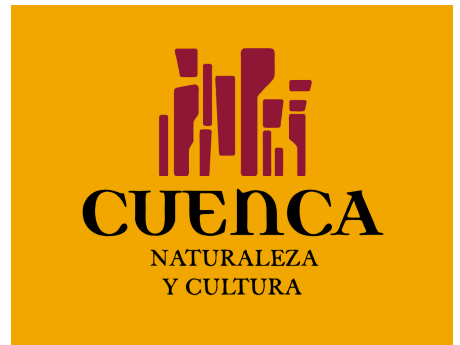

Fig. 1. Marca ciudad.

Fuente: cedida por la Fundación Turismo de Cuenca.

A la vista de las explicaciones aportadas en el Manual, se pueden extraer varias conclusiones: la primera es que la marca turística Cuenca se diseñó, en el marco del Plan de Dinamización Turística, para ser aplicada en la capital de la provincia y lograr, a través de ella, que fuera identificada y diferenciada del resto de destinos turísticos; la segunda es que tanto el símbolo, como el logotipo y el lema se atribuyen al destino de forma inmediata: el símbolo a través de su diseño abstracto pero reconocible, el logotipo porque indica explícitamente el nombre del lugar y el lema porque recoge dos atributos específicos de Cuenca; la tercera es que se desarrolló en torno a dos características singulares de Cuenca: su entorno natural y sus atractivos culturales (naturaleza y cultura) que, efectivamente, la definen y la identifican (la señalan y la determinan); y la cuarta es que la provincia de Cuenca carece de una marca que la identifique como tal.

Una vez realizado este estudio de la marca gráfica, será interesante comprobar hasta qué punto coincide el posicionamiento deseado de la misma con la imagen que se tiene de Cuenca por parte de residentes, visitantes y empresarios. Por desgracia, no existen investigaciones específicas que analicen la marca 
e imagen de marca de Cuenca (ni siquiera como destino turístico). Sin embargo, hay dos documentos de trabajo del Sistema de Investigación Turística de Castilla-La Mancha (en adelante SITdCLM) que aportan información sobre el tema. El primero de ellos (año 2008) ${ }^{1}$ analizó la marca turística y la imagen de marca de Castilla-La Mancha entre distintos grupos de profesionales y empresarios del sector turístico de la región. En uno de sus apartados se solicitó a los empresarios y profesionales del sector que, de forma espontánea, expresaran tres ideas o conceptos que definieran a las provincias en las que residían. El objetivo del estudio era elaborar la imagen individual de cada provincia como destino turístico. La conclusión más importante a la que se llegó, con respecto a Cuenca, fue que los conceptos "serranía" y "paisajes" son los que otorgan a la provincia de Cuenca un carácter único; son dos elementos relacionados con la imagen de naturaleza que se muestra en su marca turística; sin embargo, el concepto "naturaleza" no es distintivo de Cuenca, sino que es común a todas las provincias de Castilla-La Mancha. Y otro tanto sucede con el de "cultura". Por tanto, existe adecuación entre imagen y marca, pero no exclusividad.

El segundo informe del SITdCLM (año 2009)2 ${ }^{2}$, llevó a cabo el mismo tipo de análisis, pero esta vez entre grupos de empresas turísticas, residentes y visitantes en Castilla-La Mancha, así como entre esos tres segmentos en cuatro regiones españolas: La Rioja, Andalucía, Castilla y León y Extremadura. Los datos obtenidos se referían a dos universos distintos: residentes y visitantes. Los residentes opinaron que los elementos más representativos de la provincia de Cuenca son: las Casas Colgadas (24.1\%), la naturaleza (10.2\%), el conjunto patrimonial y cultural (8.8\%), la arquitectura (7.3\%) y la ciudad de Cuenca (5.8\%). Para los visitantes, la provincia conquense puede definirse a través de: las Casas Colgadas $(19.5 \%)$, la naturaleza (10.5\%), Cuenca ciudad (7.4\%), gastronomía (7\%), Serranía de Cuenca (5.8\%) y vino (5.1\%). Sí existen, en consecuencia, algunas diferencias en las ideas o conceptos asociados a Cuenca entre residentes y visitantes. Es interesante destacar, en este sentido, que sean los visitantes los que relacionan la

\footnotetext{
${ }^{1}$ Instituto de Promoción Turística de Castilla-La Mancha (IPTCLM), La marca turística de Castilla-La Mancha. SITdCLM 12. IPTCLM y Universidad de Castilla-La Mancha, 2008.

${ }^{2}$ Instituto de Promoción Turística de Castilla-La Mancha (IPTCLM), Imagen y marca turística de Castilla-La Mancha. SITdCLM) 12. IPTCLM y Universidad de Castilla-La Mancha, 2009.
} 
provincia con gastronomía, castillos, deportes de aventura y vino en mayor medida que los residentes y que, por el contrario, estos últimos lo hagan con las Casas Colgadas, el conjunto patrimonial, la arquitectura y el río Cuervo.

A la vista de lo expuesto podría concluirse que, efectivamente, Cuenca es un destino turístico que ofrece naturaleza y cultura y así es percibido por residentes y visitantes: la declaración de Cuenca como Ciudad Patrimonio de la Humanidad por la UNESCO y el abundante patrimonio existente en toda la provincia (castillos, iglesias, yacimientos arqueológicos, etc.) la convierten en un destino cultural de interior. Por otro lado, el entorno natural que el turista encuentra es rico y variado. La Ciudad Encantada y el nacimiento del Río Cuervo son dos de los elementos percibidos por residentes y visitantes como exclusivos y únicos de Cuenca. Por tanto, existe adecuación entre la marca (el lema) y su posicionamiento. Pero aun cuando la marca turística Cuenca, naturaleza y cultura define a la ciudad y cabe la posibilidad de ser utilizada también por la provincia, podríamos formular la siguiente pregunta: ¿Aporta alguna característica diferencial con relación al resto de las provincias de la comunidad o incluso con respecto a otros destinos turísticos de interior? Si la función de una marca territorio es identificar al lugar y, además, proporcionar ese valor añadido, ese rasgo distintivo que marca la diferencia con los demás competidores, parece evidente (analizados los datos) que no cumple la función de distinguir. Por ello consideramos que ha llegado el momento de retomar e impulsar el espíritu del Plan de Dinamización Turística, haciéndolo extensivo a la provincia, con el propósito de articular una estrategia coherente que aglutine a todos los agentes implicados en la toma de decisiones y que coordine las actuaciones necesarias encaminadas a mejorar los diversos productos turísticos, su promoción, comercialización y comunicación. Y, dentro de esa comunicación, es prioritaria la creación de una identidad corporativa que vaya más allá de la elaboración de una marca turística y su puesta en valor (branding). Es necesario caminar hacia el diseño de un sistema global de identificación que conlleve un posicionamiento corporativo y una estrategia de identidad y comunicación. Consideramos imprescindible la creación de una marca territorio que, superando las barreras actuales, defina y distinga a Cuenca como destino turístico.

\subsection{Dimensión social de los dinosaurios: algunos ejemplos.}

Los dinosaurios forman parte del imaginario colectivo gracias a su presencia en la literatura, el cine, la prensa o la publicidad. El interés que despiertan, pro- 
piciado también por el desarrollo de la información científica divulgativa, no es algo reciente. Autores como Conan Doyle o directores como David W. Griffith inmortalizaron a esas gigantescas criaturas a principios del siglo XX. La prensa sensacionalista se hizo eco de los "cazadores" de dinosaurios en busca de fósiles y Hollywood, siempre ávido de ideas, encontró en los "lagartos terribles" un filón de oro esperando ser explotado. Dibujos animados, personajes míticos (King Kong), e incluso anacronismos que perduran en el tiempo (la convivencia de los humanos con estos animales) han sido y son utilizados en guiones de películas con diferente resultado. En los últimos años, y gracias a la animación digital y el asesoramiento de paleontólogos, se ha evolucionado hacia una búsqueda del realismo, hecho este que ha propiciado la realización de documentales (Caminando entre dinosaurios) y de nuevas películas (Parque Jurásico) que facilitaron que los dinosaurios volvieran a convertirse en un icono cultural de nuestra época. Y eso a pesar de haber desaparecido de la faz de la tierra hace más de 60 millones de años. Es evidente, pues, que los dinosaurios despiertan el interés de adultos y de niños y que, en mayor o menor medida, atraen al público. Los medios de comunicación, dentro de su función social como difusores del conocimiento científico, han venido haciéndose eco de las noticias relacionadas con ese mundo y han divulgado los avances científicos que se producían en el terreno de la paleontología, manteniendo vivo el interés por ellos. A modo de ejemplo, citamos a continuación algunos de los yacimientos paleontológicos que más repercusión han tenido en el ámbito científico y, como una consecuencia derivada, en el sector turístico. Estudios recientes ponen de manifiesto la importancia creciente que el turismo cultural tiene en la economía de aquellos territorios que lo ofertan. En un sector cada vez más competitivo y uniforme, encontrar un elemento diferenciador es tarea necesaria, cuando no imprescindible, para atraer un mayor número de visitantes. Y los dinosaurios pueden convertirse en ese imán o catalizador.

- Drumheller (Canadá): es una ciudad situada en la provincia de Alberta, al suroeste de Canadá, cerca de Calgary. El lema que aparece en su marca la define como: El valle de los dinosaurios. Y ellos son la pieza clave del desarrollo turístico de la zona. Cuenta con uno de los museos de paleontología más importantes del mundo: el Royal Tyrrell Museum.

- Trelew (Argentina): está situada en la provincia de Chubut, en plena Patagonia. Es una de las zonas más ricas en yacimientos paleontológicos de América del Sur (junto con Neuquén). La creación del Museo Paleontológico Egidio 
Feruglio (MEF) la ha convertido en otro foco de atracción de turistas gracias al reclamo que supone la figura de los grandes dinosaurios (se calcula que el número de visitantes que acude cada año al museo supera los 70.000).

- Zigong (China): ciudad-prefectura situada en la provincia de Sichuan. Alberga uno de los museos de dinosaurios más grandes del mundo.

- Dinópolis, el caso español: situado en Teruel, Territorio Dinópolis es un parque cultural, científico y de ocio dedicado a la paleontología en general y a los dinosaurios en particular.

\subsection{Los yacimientos paleontológicos conquenses.}

Cuenca posee tres yacimientos paleontológicos de notable interés científico y social: Las Hoyas, Lo Hueco y Portilla. El primero de ellos pertenece al Cretácico Inferior (unos 120 millones de años). En él se han hallado restos de animales singulares entre los que destacan aves mesozoicas, ejemplares completamente articulados y un número importante de nuevas especies de diversos grupos, como peces y plantas (www.yacimientolashoyas.es). El yacimiento de Lo Hueco, apenas a unos kilómetros de distancia del anterior y muy cerca de Cuenca, se encuentra en el término municipal de Fuentes. Pertenece al Cretácico Superior, en el límite entre el Campaniense y el Maastrichtiense (hace poco más de 70 millones de años), lo que lo sitúa muy cerca de los últimos momentos de los dinosaurios sobre la Tierra. La abundancia de fósiles hallados y su excepcional estado de conservación ampliarán y modificarán el conocimiento que, hasta la fecha, se tenía de los saurópodos campano-maastrichtienses europeos. Por último, en el yacimiento de Portilla, cerca también de los dos anteriores, y aún sin explotar, han aparecido huevos de dinosaurios que permitirá profundizar en el conocimiento de su reproducción en Lo Hueco. Se puede hablar, por tanto, de un triángulo extraordinario, conformado por tres vértices únicos: los yacimientos citados. A nivel estratégico, el yacimiento paleontológico de Lo Hueco (junto con Las Hoyas y Portilla) cuenta con una ubicación excepcional, a una hora escasa de Madrid en AVE y a poco más de 70 minutos de Valencia. Por otro lado, Cuenca es la provincia que alberga el único Museo de las Ciencias existente en la región. Estas circunstancias, unidas a la riqueza de la zona en recursos culturales, naturales y paisajísticos, son ventajas y oportunidades que deben ser aprovechadas desde la planificación de marketing y la estrategia comunicativa a la hora de difundir el yacimiento. 


\section{El complejo de Lo Hueco: reinvención de la marca territorio conquense a través del desarrollo de eventos.}

En noviembre de 2007, el Presidente de la Junta de Comunidades de Castilla-La Mancha anunció la creación de un gran complejo científico-lúdico en torno al yacimiento de Lo Hueco, compuesto por un centro de investigación, un museo y un parque temático. El centro de investigación tendría como objetivo fundamental la conservación, estudio y difusión de todo el material paleontológico hallado en el yacimiento. El museo se centraría en coleccionar, interpretar y exhibir los restos fósiles encontrados y el parque temático trataría de ofrecer un entorno lúdico con la finalidad de atraer al mayor número de visitantes hacia las instalaciones, la divulgación científica del yacimiento y el desarrollo económico y social de la provincia.

El mercado de cualquier bien patrimonial, como es el caso del yacimiento y del proyecto que lleva asociado, estará formado por una gran variedad de públicos. Según los datos del INE, extraídos de la última Encuesta de Ocupación Hotelera referida al año 2011, las comunidades de Madrid, Valencia y Cataluña, junto con la de Castilla-La Mancha, fueron las que generaron mayor número de visitantes en Cuenca. Y también el mayor porcentaje de pernoctaciones. Estas cifras son bastante coherentes si tenemos en cuenta la situación estratégica de Cuenca, a medio camino entre Madrid y Valencia, lo que convierte a esta provincia en una de las mejores alternativas de turismo de interior por su cercanía y oferta. Por lo tanto, el público objetivo tanto del complejo de "Lo Hueco" como del resto de recursos culturales aledaños, provendrá mayoritariamente de ellas y podría definirse utilizando los siguientes parámetros:

- Residentes, entendidos como personas que viven en la zona (en el pueblo de Fuentes y aledaños). Sin olvidar colegios, asociaciones, universidad, etc.

- Visitantes, entendidos como personas dispuestas a desplazarse desde un radio de acción que puede establecerse a priori y por grados:

- Isócrona ${ }^{3} 1$, tiempo máximo de desplazamiento 60 minutos: turistas procedentes de otros lugares de la propia comunidad autónoma.

\footnotetext{
${ }^{3}$ Isócrona: Dicho de dos o más movimientos que se hacen en tiempos de igual duración (DRAE).
} 
- Isócrona 2, tiempo máximo de desplazamiento 120 minutos: turistas procedentes de Madrid y parte de Valencia y Murcia, etc.

- Isócrona 3, tiempo máximo de desplazamiento 180 minutos: turistas procedentes de Valencia, Murcia, Castellón...

- Resto de visitantes nacionales e internacionales.

- Operadores de turismo, pues ellos también van a colaborar en la difusión del evento y, por lo tanto, deben conocer todos sus pormenores de primera mano.

Tomando como referencia el estudio de viabilidad del proyecto, se puede establecer un mercado potencial estimado donde se diferencia también entre visitantes de núcleos urbanos y rurales. El número de visitantes probables se cifró en unos 270.300. Así pues, de ejecutarse el proyecto en los términos en los que está diseñado, se produciría un cambio importante en la afluencia de turistas. Ello conllevaría, en lo que atañe a esta comunicación, una oportunidad única para crear una nueva marca territorio (aprovechando la proyección social de los dinosaurios) que revitalizara y relanzara la imagen de Cuenca. Por otro lado, y utilizando como vehículo y eje vertebrador el yacimiento y el proyecto asociado, podrían difundirse el resto de recursos de la zona y de la Comunidad.

\subsection{Reinvención de la marca territorio de Cuenca.}

La imagen de Cuenca, asociada a los valores de naturaleza y cultura, es una realidad superada: tal y como se explicaba en un epígrafe anterior, esos atributos definen a la provincia pero en absoluto la diferencian del resto de competidores (ni siquiera dentro de la propia comunidad castellano-manchega). Por otro lado, la cuestión que se podría plantear es la siguiente: ¿debería explotarse el "tirón" de los dinosaurios para crear una nueva marca-territorio que defina y diferencie a Cuenca y que ayude a renombrar y reposicionar la imagen de la provincia? Nuestra opinión es que sí:

- La nueva marca territorio nos distinguiría y diferenciaría de los competidores más directos.

- Nuevo posicionamiento de Cuenca como la provincia con los yacimientos paleontológicos más importantes del Cretácico Superior e Inferior de España.

- Incorporación, a la estrategia turística y comunicativa castellano-manchega, de una nueva ruta que utilizaría a los dinosaurios como elemento aglutina- 
dor de todos los recursos alternativos al complejo "Lo Hueco" y como el vehículo ideal para difundir la marca-territorio.

Toda la comunicación se elaboraría sobre la nueva marca, sin dejar de lado los ingredientes tradicionales y ya superados (pero positivamente valorados) por residentes y visitantes: naturaleza y patrimonio. Un evento generado en torno a los dinosaurios, como es el caso del proyecto asociado al yacimiento de Lo Hueco, podría utilizarse para diseñar una nueva marca territorio $y$, al mismo tiempo, para transmitir la identidad territorial de la ciudad y la provincia. En cualquier caso, la marca territorio a implantar debería concebirse teniendo en cuenta tres elementos básicos:

- Público objetivo: Cuenca debe reposicionarse como el destino de todos aquellos que buscan un turismo de interior claramente novedoso, donde la oferta no se limita a la visita a una ciudad que es Patrimonio de la Humanidad.

- Oferta: Cuenca y su provincia, que engloba recursos lúdicos (parque temático de "Lo Hueco"), culturales (museos, yacimientos...), paisajísticos (en la propia ciudad y fuera de ella), gastronómicos, cinegéticos, de aventura... Y todo ello en un pequeño radio de acción, sin grandes desplazamientos.

- Ventajas: Una tradición turística que pervive en el tiempo, con infraestructuras adecuadas y en constante mejora y una situación geográfica estratégica, a medio camino entre Madrid y Valencia.

El gráfico de la fig. 2 (pág 168) pone de relieve la importancia que el futuro evento de "Lo Hueco" puede tener, por un lado, en la creación de una nueva marca territorio para Cuenca y, por otro, en la redefinición de su imagen.

Asistimos a una estandarización de necesidades al tiempo que se homogeniza la oferta de productos y servicios. Los destinos turísticos no escapan de este efecto globalizador $\mathrm{y}$, si quieren atraer visitantes, deben ofrecer singularidad y visibilidad. Ya no es suficiente poseer recursos culturales, naturales, gastronómicos, artesanales, etc., y disponer de una marca que los venda. Por ello, aún sin dejar de lado aquellos atributos que nos definen (naturaleza, cultura, tradición, modernidad), los dinosaurios aportan la frescura, el dinamismo, la atracción por lo desconocido y por la aventura que se necesita y que resulta imprescindible para diferenciar una marca territorio del resto que existen en el entorno. Además, es imprescindible evolucionar desde la marca de destino (orientada a los turistas) 
hacia una marca territorio que supere esa primitiva concepción y sea capaz de llegar a públicos más amplios y diversos. Una buena marca territorio, creada a partir de las características descritas, estará en condiciones de favorecer un desarrollo sostenible del entorno que garantice la conservación del patrimonio cultural y natural existente en la actualidad.

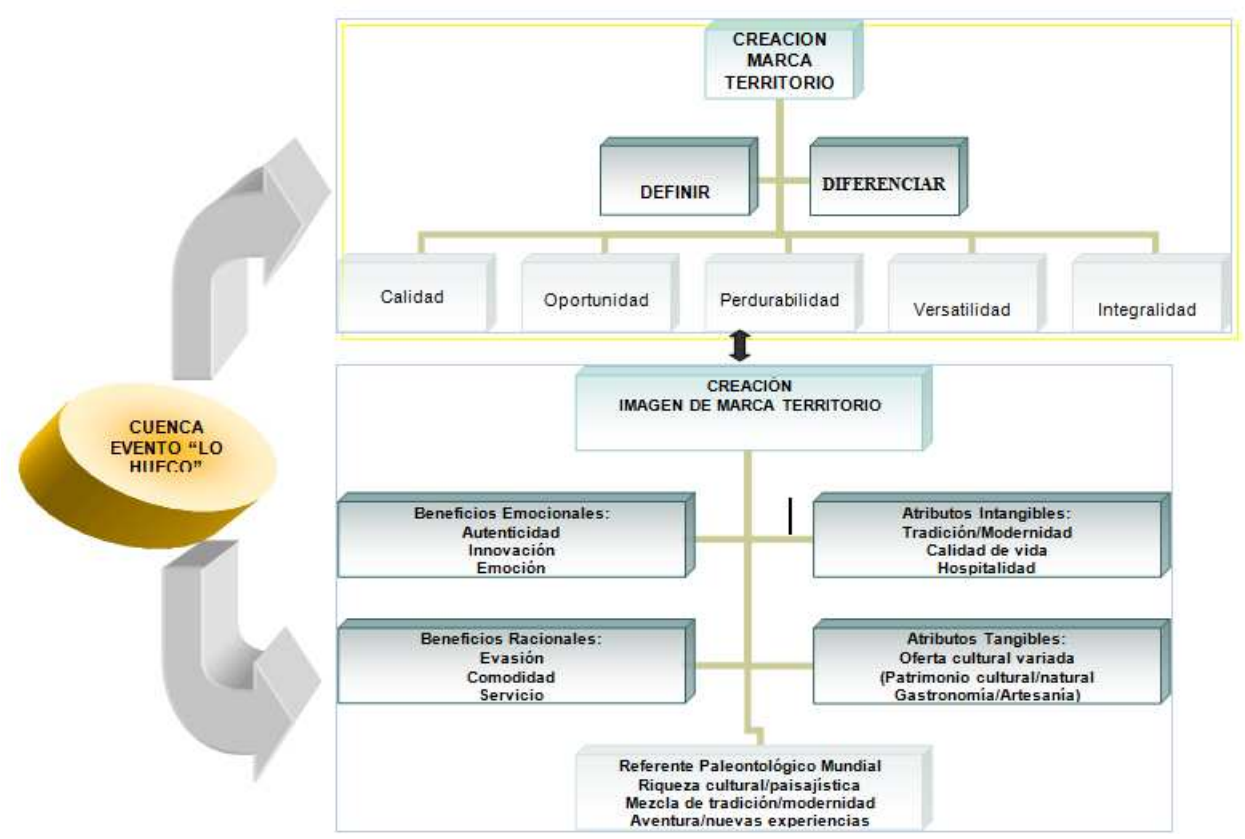

Fig. 2. Fuente: Elaboración propia a partir de Norberto Chaves, Tres generaciones en el diseño corporativo, en www.norbertochaves.com.

Por otro lado, el evento de Lo Hueco favorecerá una reinterpretación de la imagen de marca de Cuenca. Superada la visión definitoria pero no diferenciadora de Naturaleza y Cultura, los dinosaurios y la dimensión social que poseen ayudarán a conformar en la mente de los diferentes públicos objetivos una imagen distinta de la provincia, más acorde con un tipo de turismo que busca experiencias nuevas. A pesar de la cercanía de Teruel y Dinópolis, consideramos que el complejo de Lo Hueco podría aventajar a Dinópolis claramente si tenemos en cuenta una serie de factores determinantes: $1^{\circ}$ ) el complejo a construir en Fuentes podría incorporar a sus instalaciones un yacimiento vivo, donde se realizarían excavaciones puntuales en las zonas delimitadas y que aún están por explotar. Los visitantes tendrían la oportunidad de conocer de primera mano cual es el trabajo de un paleontólogo 
sobre el terreno, cómo se trabaja en una excavación, qué herramientas se utilizan habitualmente, etc. $2^{\underline{o}}$ ) El potencial científico de Lo Hueco sobrepasa ampliamente el de los yacimientos de Teruel. $3^{\circ}$ ) Las comunicaciones entre Cuenca y sus provincias limítrofes supera con claridad a las existentes actualmente en Teruel. De este modo, Cuenca y el evento de Lo Hueco, podrían constituirse como el primer ejemplo de turismo paleontológico en nuestro país (Perini y Calvo, 2008: 289).

\section{Conclusiones}

Una marca territorio implica dar vida a un concepto que, además de reunir aquellas características que son propias y diferenciales de un lugar, le aporta un valor añadido para llegar a públicos más amplios que los puramente turísticos.

El desarrollo de eventos está demostrando ser una herramienta eficaz a la hora de crear nuevas marcas territorio o nuevas imágenes de marca territorio. El impacto comunicativo que un evento puede tener depende, en buena medida y en la mayoría de los casos, de los planes de desarrollo articulados en cada caso.

La marca ciudad Cuenca, naturaleza y cultura define dos de los atributos tangibles más importantes que posee la ciudad y su provincia. Pero no la distingue, no aporta ningún rasgo diferencial con respecto a otros destinos competidores, dentro y fuera de Castilla-La Mancha. Se limita a describir una realidad.

La riqueza paleontológica de la provincia conquense la sitúa en un puesto privilegiado a la hora de explotar, comunicativamente, la dimensión social que los dinosaurios poseen. Además, la ejecución futura del evento Lo Hueco puede ser crucial a la hora de proponer un nuevo atributo que defina y diferencie a Cuenca del resto de los territorios competidores.

El evento Lo Hueco podría utilizarse como el vehículo capaz de lanzar al mercado una nueva marca territorio para Cuenca y una imagen de marca diferente, basada en los dinosaurios. Además, Cuenca estaría en condiciones de ser el primer referente nacional de turismo paleontológico.

\section{Bibliografía}

BLAIN, C.; LEVY, S.E.; BRENT RITCHIE, J.R. (2005): “Destination Branding: Insights and Practices from Destination Management Organizations". Journal of Travel Reseach. 
CALlARISA, L.J. (2010): “La identidad del territorio, factor estratégico". IV Foro Innovem Junts: El territorio, factor estratégico. En www.innovemjuntcv.org. Consultado el 15/06/2012.

CASSISI, L. (2006): Marca y marca gráfica. En: foroalfa.org/articulos/marca-ymarca-grafica. Consultado 05/07/2012.

CostA, J. (2004): La imagen de marca. Un fenómeno social. Paidós, Barcelona.

FERNÁNDEZ, J. y HUERTAS, A. (2009): “City brands and their communication through websites: Identification of problems and propoals for improvement". TORRES \& GASCó (Eds.), Information Communication Technologies and City Marketing: Digital Opportunities for Cities around the World, IGI Global, Hershey.

HuerTAS, A. (2010): Las claves del Citybranding. Institut de la Comunicació, Portal de la Comunicación, Bellaterra, Universitat Autónoma de Barcelona. www.portalcomunicacion.com/esp/pdf/aab_lec/57.pdf. Consultado 08/06/2012.

JIMÉNEZ, M. y SAN EUGENIO, J. (2009): “Identidad territorial y promoción turística: la organización de eventos como estrategia de creación, consolidación y difusión de la imagen de marca del territorio". ZER Revista de Estudios de Comunicación, no 26, UPV/EHU, Bilbao. En www.ehu.es/zer/ es/hemeroteca/articulo/identidad-territorial-y-promocion-turisticala-organizacionde-eventos-como-estrategiade-creacion-consolidacion-y-difusionde-la-imagen-demarca-del-territorio/393. Consultado 22/05/2012.

KANDAMPUlly, J. (2000): The Impact of Demand Fluctuation on the Quality of Service: A Tourism Industry Example. Managing Service Quality.

Keller, K. (2008): Administración estratégica de marca: Branding. Pearson Educación, México.

PERINI, M. y CALVO, J. (2008): Paleontological Tourism: an alternative income to vertebrate paleontology. Arquitos do Museu Nacional, Río de Janeiro.

Plan de Dinamización Turística de Cuenca (2001). Manual de Identidad Corporativa, Mo de Economía y Hacienda, Junta de Comunidades de Castilla-La Mancha, Ayuntamiento de Cuenca y Agrupación Provincial de Hostelería y Turismo, Cuenca.

PUIG, T. (2009): Marca ciudad. Como rediseñarla para asegurar un futuro espléndido para todos. Paidós, Barcelona.

SEMPRINI, A. (1995): El marketing de la marca: una aproximación semiótica. Paidós, Barcelona.

WORLD TOURISM ORGANIZATION AND THE EUROPEAN TRAVEL COMISIÓN (2009): Handbook on Tourism Destinations Branding. Madrid. 